\title{
Detection and quantification of pulmonary emphysema by computed tomography: a window of opportunity
}

The identification and precise quantification of pulmonary emphysema in life are an attractive proposition, but are made virtually impossible by the pathological basis of its definition. ${ }^{1}$ The normal lung contains millions of small airspaces and early identification of their destruction is likely to be difficult and, although there are correlations between the more severe grades of emphysema and radiological or physiological abnormality, they are not especially close. Modern computed tomography scanners can examine the lung parenchyma directly with a resolution of less than $0.5 \mathrm{~mm}$ and may have the ability to detect and quantify emphysematous change more precisely. Ten years have passed since the first enthusiastic publication of the description of emphysema based on computed tomography. ${ }^{2}$ In the same period there have also been important improvements in the technology and validation of computed tomography applied to lung disease, so it is now appropriate to see whether the technique has lived up to expectations.

Pulmonary emphysema is characterised by abnormal, permanent enlargement of airspaces distal to the terminal bronchiole accompanied by the destruction of their walls. The condition is usually determined by examination of postmortem or resection specimens. Identification of the condition in life not only allows assessment of the extent of damage but also paves the way for epidemiological studies of emphysema as well as interventions such as antiprotease replacement and persuading the patient to give up smoking. Before computed tomography was used the best estimate of the presence of emphysema was based on a combination of conventional radiology and physiological tests.

The plain chest radiograph is unable to show the lung without the interference of the chest wall structures, through which the $x$ rays must also pass. The image is therefore composite and the assessment of lung density is imprecise even if the film is scanned by densitometer. ${ }^{3}$ The presence of emphysema can be gauged indirectly by the appearance of hyperinflation or by deficiency in the pulmonary vasculature. Hyperinflation, which is not confined to emphysema, is best seen from the flattening of the diaphragm and to a lesser extent from the expansion of the retrosternal space. ${ }^{4}$ Sometimes bullae may be obvious on the chest film but appreciable bulla formation may go unnoticed if normal lung is interspersed between the bulla and the chest wall. Peripheral oligaemia in the lung fields with prominence of the hilar vessels may be characteristic of severe emphysema; but lesser degrees of attenuation of vessels may be more difficult to spot, particularly if it is patchy.

Many studies have compared the radiological appearance and grading of emphysema at necropsy, though obviously these cannot have not been contemporary. ${ }^{5-9}$ The comparisons in these studies were usually between the radiological features and sagittal sections of lung, which were carefully prepared by inflation and paper mounting. The sections were subject to grid or panel grading and the results compared with the radiological features in life. The overall accuracy of conventional radiography in the detection of emphysema ranges from $65 \%$ to $80 \%$, but the sensitivity is poor in mild disease. Hyperinflation on the chest radiograph is a reliable though non-specific feature of severe emphysema, but mild and moderate disease cannot be detected by plain radiography.
Pulmonary function abnormalities produced by emphysema include airway obstruction, hyperinflation, and disturbance of gas exchange manifested by reduced single breath carbon monoxide transfer factor (TLCO). Although the latter is widely believed to be helpful in the detection of emphysema, values do not relate well to the grade of disease.$^{10}$ In addition, none of these features are specific to emphysema, which may be present despite nearly normal results in conventional lung function tests. Reduction in pulmonary elastic recoil pressure is a more sensitive guide to the presence of emphysema, but may still not detect mild disease. ${ }^{11} 12$

The image of the lung produced by computed tomography is a transverse section independent of the size and shape of the patient. The attenuation values of the internal structures are proportional to physical density. These values are expressed in Hounsfield units, which are referenced to air $(-1000 \mathrm{HU})$ and water $(0 \mathrm{HU})$. Each element of the final picture, or pixel, will have an attenuation value. Modern scans are reconstructed with a $512 \times 512$ matrix and spatial resolution is governed by the chosen field of view. When the image target is reduced to about $13 \mathrm{~cm}$ with a pixel size of $0.25 \mathrm{~mm}$ the resolution will be 1.5 times the pixel size. The pixel density is determined by the thickness of the slice producing the image and the type of tissue within the volume element, or voxel. The lung pixel density varies from -600 to $-900 \mathrm{HU}$ and is determined by the relative amounts of blood, tissue, and air contained in the voxel. There is a normal hydrostatic gradient of about $-200 \mathrm{HU}$ from the top to the bottom of the lung slice at functional residual capacity, which decreases during inspiration. ${ }^{13}$ The scan time of most modern scanners allows images to be obtained in breath hold at any stage of the breath cycle, when the mean density values of the lung also decrease during inspiration. In emphysema there is a relative reduction in the quantity of blood and tissue within the voxel, and the pixel density in severe disease will approach or reach a value of $-1000 \mathrm{HU}$. The technical options that relate to the imaging of emphysema include the position of the breath hold in the inspiratory capacity, the width of the slice, and the number of slices necessary to satisfy the requirement for detection or quantification.

There are two main approaches to the study of emphysema by computed tomography. The first is the detection and quantification of disease by visual inspection and grading. The second, more hopeful, development is the use of the attenuation values for the automatic measurement of lung density or tissue mass. Both of these approaches have been validated by increasingly sophisticated pathological and physiological comparison. So far the investigation of the relation between images and pathological features has been confined to confirming statistical correlation.

\section{Visual methods}

When the lung is imaged with the appropriate window (centre -650 , width $1500 \mathrm{HU}$ ) the appearance of centrilobular emphysema is characteristic. The parenchyma contains areas of low density without clear margins, the blood vessels show peripheral attenuation, and the normal ventrodorsal density gradient is disrupted. Areas of bulla formation may also be easily identified by visual inspection. In one of the first studies evaluating computed tomography 
in the assessment of emphysema, Goddard and colleagues developed a visual score based on the appearance of the blood vessels and areas of low density in each of eight slices, taken from the apex to the lung base, each in arrested inspiration. ${ }^{2}$ The scores in patients with chronic lung disease and the clinical appearance of emphysema differed significantly from those in normal volunteers and were inversely correlated with $\mathrm{FEV}_{1}$ and TLco. Computed tomography clearly showed the absence of tissue destruction in some patients with radiological hyperinflation and preserved TLCO. Later studies by Forster and Bergin used similar visual scoring systems to identify moderate emphysema and relate the degree of centrilobular emphysema in patients who eventually came to postmortem examination or had resections to the computed tomography score. ${ }^{1415}$ To increase the accuracy of the technique Hruban et al examined the value of high resolution image reconstruction with $8 \mathrm{~mm}$ collimation in postmortem lung specimens in vitro. ${ }^{16} \mathrm{He}$ compared the resulting images with the pathological specimens cut in the same plane as the computed tomogram, and the correlation $(r=0.91)$ included the lowest grades of emphysema defined by pathological panel grading. Miller et al examined the potential sensitivity further by comparing thick and thin computed tomography slices with the resected specimens graded according to a more rigorous pathological grid scoring system. ${ }^{17}$ They concluded that, although narrow section computed tomography was superior, it could still underestimate the degree of panacinar emphysema if the lesions were less than $0.5 \mathrm{~cm}$. The sensitivity of computed tomography in this context will increase as the technology and image resolution improve. A more recent paper, by Kuwano et al, who also used resected specimens, describes the use of $5 \mathrm{~mm}$ and $1 \mathrm{~mm}$ high resolution sections to detect mild emphysema. ${ }^{18}$ Interestingly, the narrow section is not a major advance because, although it shows parenchymal destruction well, it is not so good at showing the vascular changes.

Visual inspection of the hard copy of the computed tomography image can therefore reliably detect and grade pulmonary emphysema to the current limit of resolution of computed tomography. The drawbacks of visual techniques, however, relate to the experience of the observer. The method is time consuming and skill dependent and there is an inherent $10 \%$ intraobserver and interobserver variability. The different window settings used by different observers may also produce discrepancies. The exclusion of the human element by use of the original digital information would avoid these sources of error and increase the potential accuracy and sensitivity of the method.

\section{Automated quantification of emphysema}

The automatic calculation of the tissue mass and density of the lung is made possible by computed tomography. Some practical and theoretical problems, however, have inhibited its development. The major problems include the identification of the boundaries of the lungs and the considerable additional computer processing required. The computed tomography density does not relate precisely to actual density because several assumptions may be made in the use of the $x$ ray intensities to produce the best image. The detected $x$ ray intensities are filtered and corrected for beam hardening as they pass through the body and the final image is reconstructed from many different single beams. Nevertheless, computed tomography can reliably recover the density of solid objects, artificial foams, and animal lungs. ${ }^{190}$ In life the position is further complicated by artefacts produced by respiratory and cardiac movements and also by the partial volume effect. The latter is a particular problem at the boundaries of the lung, where many pixels will contain portions of adjoining, often high density, tissue.

Some studies have examined the potential of computed tomography to measure the density of the lung and therefore quantify emphysema by automated techniques. The initial requirement of any automatic process for measuring lung density is the apparently simple identification of the lung boundaries. With visual inspection it is easy to see where the boundaries might be, but to measure density accurately these boundaries must be precise and reproducible. Identification of the boundaries with exclusion of the major blood vessels (less than $5 \mathrm{~mm}$ ) must be made by a manual step before analysis of the lung fields. This usually includes the identification of a "region of interest" that incorporates the lung. This can also be done automatically by means of edge tracking or contiguous pixel computing routines that minimise intervention by the operator.$^{21}{ }^{22}$ Once the boundaries are defined it is an easier matter to compute the mass and volume of each slice of the scan. The tissue mass and whole lung density is then obtained by scanning the whole lung in contiguous slices and summing the values for each slice. Measurements of in vivo lung density have been made in healthy lungs and in fibrotic and emphysematous lungs and they compare well with the results of morphometric studies. ${ }^{23}{ }^{24}$ Interestingly, although lung density is confirmed to be reduced in emphysema it is not reduced very much and the actual total tissue mass of the lung is greater than normal. The change in compliance of the emphysematous lung does increase the vertical ventrodorsal density gradient, thus showing that this gradient has both tissue and hydrostatic components. ${ }^{25}$

Automatic measurements of whole lung density have great scientific interest but two difficulties. Firstly, they require additional external computing facilities and also the whole lung needs to be scanned. A second approach to the quantitative study of emphysema is to scan selected areas of lung tissue with commercial software incorporated in the single imaging machine. The standard software easily obtains mean lung density values but these have not proved sufficiently sensitive to be useful. The minor changes in mean density with emphysema are overshadowed by the variable vascular contribution. ${ }^{26}$ Other routes have been explored and the Edinburgh group has used statistical analysis of the lung fields to study patients with emphysema before lung resection. ${ }^{27}$ They obtained a frequency distribution of pixels, the lowest 5 th percentile correlating well with TLCO, and an elegant pathological estimate of airspace destruction.

An alternative approach has been to quantify the pixels beyond a density threshold. This is known as a "density mask" and Muller and colleagues have used a threshold of $-910 \mathrm{HU}$ to obtain the area of emphysema in each slice. ${ }^{29}$ The results correlated very well $(r=0.94)$ with the pathological grades of resected specimens and were better than the results of visual scoring of the computed tomogram. One of the problems with all of these techniques is the difficulty of distinguishing hyperinflation from emphysema. Few workers have been brave enough to include patients with asthma or non-emphysematous airflow obstruction in their studies. Recently Knudsen et al have reported the use of a density mask technique that uses a limited examination in full inspiration and full expiration with a mask threshold of $-900 \mathrm{HU} .^{30} \mathrm{An}$ increase in the mean percentage of pixels in the expiratory scans appeared to indicate emphysema and distinguish it from hyperinflation without tissue destruction.

Comparison of computed tomography with chest radiography and lung function tests

Most investigations of the value of computed tomography 
in emphysema have concentrated on comparison with pathology. Some studies have incidentally compared the accuracy and sensitivity of computed tomography with those of plain radiology and tests of lung physiology. ${ }^{14}{ }^{15} \mathrm{~A}$ few studies have had this as their main objective. ${ }^{30-33}$ Computed tomography is much more sensitive than plain radiography $(96 \% v 68 \%)$ in detection of established emphysema.

The functional abnormalities in emphysema include airflow limitation, hyperinflation, diminished TLCO, and increased compliance. The extent of emphysema as determined by visual and automatic grading of the computed tomogram relates most strongly to compliance and TLCO, and less well to $\mathrm{FEV}_{1}$. $^{34}$ Examination of the separate capillary blood volume (VC) component of TLCo does not produce a stronger correlation with the computed tomography grades. ${ }^{35}$ The extent of emphysema on the computed tomogram does not predict any of the haemodynamic or gas exchange disturbances that characterise respiratory failure in emphysema. ${ }^{36}$ This highlights the unpredictability of the effect of pathological change on physiological function and the relative insensitivity of lung function tests. Even at the current level of technology computed tomography can detect early anatomical emphysema in smokers who have normal results in pulmonary function tests. ${ }^{37} 38$

\section{Assessment of emphysematous bullae}

Most patients with emphysema have diffuse or multifocal disease. Occasionally the destructive process selectively affects one region of lung, preferentially leading to the establishment of a large bulla. This may occur with or without generalised emphysema in the adjacent tissues and the functional effects of the bulla may be difficult to distinguish from those of the background disease. It is important to assess these cases correctly because appropriate surgery for isolated bullae may produce a dramatic improvement. Bullae are well identified by computed tomography and their volume and ventilation can be estimated. ${ }^{39}$ More than one slice must be examined because bullae become distorted during the course of the breath. The estimates of ventilation confirm that most bullae do not change their volume during respiration. Consequently tests of airway function and gas exchange must reflect the quality of the remainder of the lung rather than the bulla. Apart from helping to understand the mechanisms of bullous lung disease computed tomography has become an essential investigation before surgery. ${ }^{41}$ The images tell the surgeon the size and position of the bulla as well as describing the quality of the surrounding lung. ${ }^{42}$ Such information is central to the decision about whether to operate as well as the actual choice of surgical procedure.

\section{The future}

The application of computed tomography to the study of emphysema has come a long way in the past decade. Although the detection of emphysema by visual grading is limited by the resolution of the scanner, and may never be perfect, this method can already detect early disease in patients with normal results in respiratory function tests. Simple visual inspection may be adequate but the development of a grading system is important for epidemiological study or assessment of disability. With this in mind, a new standardised scoring method for high resolution computed tomography, analogous to the ILO system for grading chest radiographs, has been described by Jarad and colleagues, which should be helpful. ${ }^{43}$ The other successes of the visual interpretation of the computed tomogram include the assessment of bullous disease and the differentiation of emphysema from fibrosing alveolitis when they coexist. ${ }^{44}$

The development of automatic quantification of emphysema is more difficult because there is currently no accepted standard method. Future standardisation will require guidelines on the suitability of machines and on internal software and calibration. Respiratory gating with exposure triggered by the required phase of inspiration will also reduce errors. ${ }^{45} \mathrm{We}$ should begin to see results of some studies that have examined the true agreement between computed tomography and pathology rather than obtaining correlation estimates. Cost and radiation exposure are likely to favour sampling techniques rather than whole lung measurements.

Evidence already suggests that detection of emphysema by computed tomography has become a useful tool in the understanding of disease. One example is the discovery that emphysema in silicosis is related to smoking and not to industrial exposure. ${ }^{46}$ Probably computed tomography is also now sensitive enough to follow the longitudinal development of emphysema. ${ }^{47}$ We may look forward to the consolidation and standardisation of techniques over the next decade and the derivation of estimates of emphysematous disease from computed tomography with their application to the real clinical problems.

MICHAEL D L MORGAN Department of Respiratory Medicine, Glenfield Hospital, Leicester LE3 $9 Q P$

Reprints will not be available.

Glenfield Hospital,
Leicester LE3 9QP

1 Snider GL, Kleinerman J, Thurlbeck WM, Bengali ZH. The definition of emphysema. Am Rev Respir Dis 1985;132:182-5.

2 Goddard PR, Nicholson EM, Laszlo G, Watt I. Computed tomography in pulmonary emphysema. Clin Radiol 1982;33:379-87.

3 Laws JW, Steiner RE. $X$ ray densitometry in the study of pulmonary ventilation and the pulmonary circulation. $B r J$ Radiol 1965;38:512-8.

4 Simon G. Radiology and emphysema. Clin Radiol 1964;15:293-306.

5 Pratt PC. Role of conventional chest radiography in diagnosis and exclusion of emphysema. Am J Med 1987;82:998-1006.

6 Sanders C. The radiographic diagnosis of emphysema. Radiol Clin North Am 1991;29:1019-30.

7 Thurlbeck WH, Simon G. Radiographic appearance of the chest in emphysema. AJR 1978;130:429-40.

8 Nicklaus TM, Stowell DW, Christiansen WR, Renzetti AD. The accuracy of roentgenological diagnosis of chronic pulmonary emphysema. Am Rev Respir Dis 1966;93:889-99.

9 Reid L, Millard FJC. Correlation between radiological diagnosis and structural changes in emphysema. Clin Radiol 1964;15:306-11.

10 Nagai A, West WW, Thurlbeck WM. The National Institutes of Health intermittent positive pressure breathing trial. II. Correlation between morphological findings, clinical findings and evidence of expiratory air-flow obstruction. Am Rev Respir Dis 1985;132:946-53.

11 Pare PD, Brooks LA, Bates J, Lawson LM, Nelems JMB, Wright JL, et al. Exponential analysis of the pressure-volume curve as a predictor of pulmonary emphysema. Am Rev Respir Dis 1982;126:54-61.

12 Petty TL, Silvers GW, Stanford RE. Mild emphysema is associated with reduced elastic recoil and increased lung size but not with airflow limitation. Am Rev Respir Dis 1987;136:867-71.

13 Robinson PJ, Kreel L. Pulmonary tissue attenuation with computed tomography: comparison of inspiration and expiration scans. J Comput Assist Tomogr 1979;3:740-8.

14 Forster WL, Pratt PC, Roggli VL, Godwin JD, Halvorsen RA, Putman CE. Centrilobular emphysema: CT-pathologic correlation. Radiology 1986; 159:27-32.

15 Bergin C, Muller N, Nichols DM, Lillington G, Hogg JC, Mullen B, et al. The diagnosis of emphysema: a computed tomographic-pathologic correlation. Am Rev Respir Dis 1986;133:541-6.

16 Hruban RH, Meziane MA, Zerhouni EA, Khouri NF, Fishman EK, Wheeler PS, et al. High resolution computed tomography of inflation-fixed lungs. Am Rev Respir Dis 1987;136:935-40.

17 Miller RR, Muller NL, Vedal S, Morrison NJ, Staples CA. Limitations of computed tomography in the assessment of emphysema. Am Rev Respir Dis 1989;139:980-3.

18 Kuwano K, Matsuba K, Ikeda T, Murakami J, Araki A, Nishitani H. The diagnosis of mild emphysema. Am Rev Respir Dis 1990;141:169-78.

19 Hedlund LW, Vock P, Effmann EL. Computed tomography of the lung: densitometric studies. Radiol Clin North Am 1983;21:775-88.

20 Hedlund LW, Effmann EL, Bates M, Bowyer K, Putman C. A comparison of lung density measured gravimetrically and by computed tomography [abstract]. Invest Radiol 1982;17:S11.

21 Hedlund LW, Anderson RF, Goulding PL, Beck JW, Effmann EL, Putman CE. Two methods for isolating the lung area of a CT scan for density information. Radiology 1982;144:353-7. 
22 Fromson BH, Denison DM. Quantitative features in the computed tomography of healthy lungs. Thorax 1988;43:120-6.

23 Denison DM, Morgan MDL, Millar AB. Estimation of regional gas and tissue volumes of the lung in supine man using computed tomography. Thorax 1986;41:620-8.

24 Millar AB, Fromson BH, Srickland BA, Denison DM. Computed tomography based estimates of regional gas and tissue volume of the lung in supine subjects with chronic airflow limitation or fibrosing alveolitis. Thorax 1986;41:932-9.

25 Millar AB, Denison DM. Vertical gradients of lung density in supine subjects with fibrosing alveolitis or pulmonary emphysema. Thorax 1990; 45:602-5.

26 Pugatch RD. The radiology of emphysema: Clin Chest Med 1983;4:433-42.

27 Hayhurst MD, Flenley DC, McLean A, Wightman AJA, MacNee W, Wright $\mathrm{D}$, et al. Diagnosis of pulmonary emphysema by computerised tomography. Lancet 1984;ii:320-2.

28 Gould GA, MacNee W, McLean A, Warren PM, Redpath A, Best JJK, et al. CT measurements of lung density in life can quantitate distal airspace enlargement an essential defining feature of human emphysema. $\mathrm{Am} \mathrm{Rev}$ Respir Dis 1988;137:380-92.

29 Muller NL, Staples CA, Miller RR, Abboud RT. Density mask: an objective method to quantitate emphysema using computed tomography. Chest 1988;94:782-7.

30 Knudsen RJ, Standen JR, Kaltenborn WT, Knudsen DE, Rehm K, Habib MP, et al. Expiratory computed tomography for assessment of suspected pulmonary emphysema. Chest 1991;99:1357-66.

31 Kinsella M, Muller NL, Abboud RT, Morrison NJ, DyBuncio A. Quantitation of emphysema by computed tomography using a density mask program and correlation with pulmonary function tests. Chest 1990; 97:315-21.

32 Sanders C, Nath PH, Bailey WC. Detection of emphysema with computed tomography: correlation with pulmonary function tests and chest tomography: correlation with pulmonar

33 Sakai F, Gamsu G, Im Jung-Gi, Ray CS. Pulmonary function abnormalities in patients with CT determined emphysema. J Comput Assist Tomogr 1987;11:963-8.

34 Gould GA, Redpath AT, Ryan M, Warren PM, Best JJK, Flenley DC, et al. Lung CT density correlates with measurements of airflow limitation and the diffusing capacity. Eur Respir J 1991;4:141-6.
35 Morrison NJ, Abboud RT, Muller NL, Miller RR, Gibson NN, Nelems B, et al. Pulmonary capillary blood volume in emphysema. Am Rev Respir Dis 1990;141:53-61.

36 Biernacki W, Gould GA, Whyte KF, Flenley DC. Pulmonary haemodynamics, gas exchange and the severity of emphysema as assessed by quantitative CT scan in chronic bronchitis and emphysema. Am Rev Ruantitative CT scan in chronic Dis 1989;139:1509-15.

37 Wolmer P, Albrechtson U, Brauer K, Erikson L, Jonson B, Tylen U. Measurement of pulmonary density by means of $X$ ray computerised tomography. Chest 1986;90:387-91.

38 Klein JS, Gamsu G, Webb WR, Golden JA, Muller NL. High resolution CT diagnosis of emphysema in symptomatic patients with normal chest radiographs and isolated low diffusing capacity. Radiology 1992;182: radiograph $817-21$.

39 Morgan MDL, Strickland B. Computed tomography in the assessment of bullous lung disease. $B r J$ Dis Chest 1984;78:1025.

40 Morgan MDL, Denison DM, Strickland B. The value of computed tomography for selecting patients with bullous lung disease for surgery. Thorax 1986;41:855-62.

41 Morgan MDL, Edwards CW, Morris J, Matthews HR. The origin and behaviour of emphysematous bullae. Thorax 1989;44:533-8.

42 Klingman RR, Angelillo VA, DeMeester TR. Cystic and bullous lung disease. Ann Thorac Surg 1991;52:576-80.

43 Jarad NA, Wilkinson P, Pearson MC, Rudd RM. A new high resolution computed tomography scoring system for pulmonary fibrosis, pleural disease and emphysema in patients with asbestos related disease. $\mathrm{Br} J$ Ind Med 1992;49:73-84.

44 Wiggins J, Strickland B, Turner-Warwick M. Combined cryptogenic fibrosing alveolitis and emphysema: the value of high resolution computed tomography in assessment. Respir Med 1990;84:365-9.

45 Kalender WA, Fichte H, Bautz W, Skalej M. Semiautomatic evaluation procedures for quantitative CT of the lung. J Comput Assist Tomogr 1991; 15:248-55.

46 Kinsella M, Muller N, Vedal S, Staples C, Abboud RT, Chan-Yeung M. Emphysema in silicosis. Am Rev Respir Dis 1990;141:1497-500.

47 Noma S, Herman PG, Khan A, Rojas KA, Pipman Y. Sequential morphologic changes of elastase-induced pulmonary emphysema in pigs. Invest Radiol 1991;26:446-53. 